\title{
7Research Paper \\ The Effectiveness of Parent-Based Play-Therapy on Aggression and and Symptoms of Oppositional Defiant Disorder
}

\author{
Akram Akbari $^{1}$, Nader Monirpour ${ }^{* 2}$, Hassan Mirzahosseini ${ }^{2}$ \\ 1. Ph.D. Student in General Psychology, Department of Psychology, Qom Branch, Islamic Azad University, Qom, Iran \\ 2. Assistant Professor, Department of Psychology, Qom Branch, Islamic Azad University, Qom, Iran
}

Citation: Akbari A, Monirpour N, Mirzahosseini H. The effectiveness of parent-based play-therapy on aggression and and symptoms of oppositional defiant disorder. J Child Ment Health. 2021; 8 (1):126-140.

URL: http://childmentalhealth.ir/article-1-1098-en.html
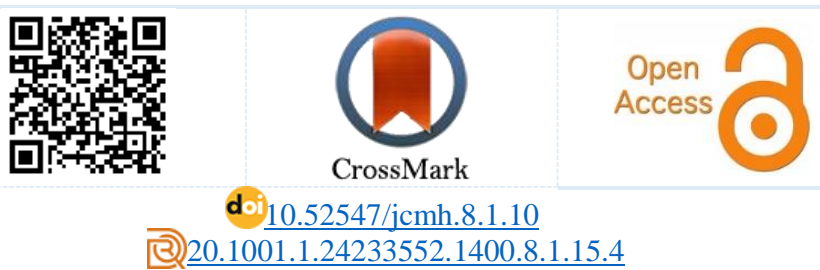

\section{A R T I C L E I N F O}

\section{Keywords:}

Parent-based play

therapy, aggression, oppositional defiant disorder

Received: 13 Jan 2021 Accepted: 14 Jun 2021 Available: 21 Jun 2021

\section{A B S T R A C T}

Background and Purpose: The onset of the oppositional defiant disorder (ODD) occurs in childhood and preschool age; and if left untreated, it can make many imposed costs on the child, family, and community, so appropriate interventions for children with this disorder are required; therefore, the aim of this study was the effectiveness of parent-centered play-therapy on aggression and symptoms of ODD.

Method: The present study was a quasi-experimental pretest-posttest with a control group. From the statistical population that included all children aged 4-5 years with ODD referred to Setarehshahr Kindergarten and Preschool in District 14 of Tehran in the second six months of 2019, 30 eligible children were selected by convenient sampling method and randomly assigned into two experimental and control group (15 persons in each group). The Gado and Sprafkin (2002) Child Symptoms Questionnaire and the Achenbach and Rescorella (2001) Child Behavior Inventory were used to collect data. Parent-based Play Therapy Educational Intervention (Barton and Landarth, 2006) was presented to the experimental group in 8 sessions of 60 minutes, while the control group did not receive educational training. Data were analyzed using SPSS software version 22 and univariate analysis of covariance at the significance level of 0.05 .

Results: The results showed that parent-centered play therapy was effective in reducing aggression and syptoms of ODD symptoms $(\mathrm{p}<0.01)$

Conclusion: Parent-centered play therapy provides effective and beneficial strategies to reduce aggression and ODD symptoms; therefore, the use of this model in medical and counseling centers is recommended to promote mental health.

* Corresponding author: Nader Monirpour, Assistant Professor, Department of Psychology, Qom Branch, Islamic Azad University, Qom, Iran.

E-mail: Monirpoor1357@gmail.com

Tel: (+98) 2188785266

2476-5740/ (C) 2021 The Authors. This is an open access article under the CC BY-NC-ND license

(https://creativecommons.org/licenses/by-nc-nd/4.0/). 


\section{Extended Abstract}

\section{Introduction}

The third most common psychiatric disorder in children and adolescents is oppositional defiant disorder (ODD) (1). It is a pattern of restless mood and behavior, contradiction and disobedience, resentment, rashness, rage, and law-breaking behaviors that last more than six months and in which at least four signs in interaction with at least one person other than siblings are revealed (3). The affected children have a low self-concept, low selfesteem, learned helplessness, depression, low tolerance for failure, and aggression due to coping behaviors and consequently poor education and communication with others $(10,11)$.

Various (individual and family) therapies have been used to the reduction of the behavioral, cognitive, and emotional problems of children with ODD. Among these therapies, one of the most effective methods of play therapy is parent-centered play therapy that has been called the child-parent relationship therapy model by Landarth and Barton (33). Child-parent relationship therapy is a playbased communication model for children of 3-10 years old who may be experiencing emotional or behavioral distresses (19). This therapeutic model consists of lecturing, discussing, role-playing, and group processes in which parents, through roleplaying, teach their children skills such as reflection of emotion, behavior, and empathy (20). In general, child-parent relationship therapy is an intervention that emphasizes the relationship between child and parent and its main purpose is to improve the childparent relationship by creating a sense of trust, interest, and mutual understanding. Parents learn how to create and strengthen a non-judgmental, consensual, and receptive environment that facilitates personal growth and change in the child and parents (21). The effectiveness of child-parent relationship therapy has been confirmed on reducing aggression in primary school children with ODD (22), on reducing preschool children's aggression (23-24), on students' behavioral problem-solving (25), on reducing the symptoms of ODD in children aged 2-7 years and on behavioral issues and adaptability of aggressive and disobedient children
(26). The important role of play-based parental therapy in the treatment process and reduction of aggression problems, shows the need to evaluate its effectiveness. Determining the effectiveness of this play therapy model requires countless studies and researches that this study has been done in this direction. Therefore, the present study aimed to determine the effectiveness of parent-centered playtherapy on aggression and symptoms of ODD.

\section{Method}

The present study was a quasi-experimental one with a pretest-posttest design and a control group. The statistical population was children aged 4-5 years with ODD referred to Setareh Shahr Kindergarten and Preschool (under the supervision of Tehran Welfare Organization) in District 14 of Tehran in the second six months of 2019. Among them, 30 eligible individuals were selected by convenint sampling method and randomly assigned in two experimental and control groups (15 individuals each group). The inclusion criteria for the study were the diagnosis of a child's ODD by the psychologist of the center, the child being 4-5 years old and attending kindergarten, having no disability or comorbid disorder, and having the consent of the child and mothers to cooperate and participate in experiments. Exclusion criteria included experiencing severe physical and mental health issues and receiving other medication or psychotherapy for the child and their mothers. According to the results obtained from 30 participants, 15 participants were in the experimental group, and 15 participants were in the control group. Also, the mean and standard deviation of the age of the participants in the experimental group was $4.24 \pm 1.18$, and it was $4.19 \pm 1.26$ for the control group. In the experimental group, there were seven boys $(46.7 \%)$ and eight girls (53.3\%), and in the control group, there were eight boys $(53.3 \%)$ and seven girls (46.7\%). To collect data, Gado and Sprafkin's Child Symptoms Inventory (29) and Achenbach and Rescorla's Child Behavior Checklist (31) were used (Iranian version). The research method was such that after selecting the sample and assigning them into experimental and control groups, individuals in both groups were tested as a pre-test using research subscales, then the experimental 
group received interventions including eight childparent relationship therapy sessions (60 minutes per session and two sessions per week), but the control group did not receive any intervention. At the end of the intervention, the participants of the two groups were retested with research scales. Data were analyzed with univariate analysis of covariance (ANCOVA) by using the SPSS-22 software.

\section{Results}

The mean and standard deviation of pre-test and post-test scores of aggressions and ODD symptoms variables of the two experimental and control groups are present in Table 1. Skewness and kurtosis ratios also have been reported to test the normality assumption of the distribution of variables. Since that the values of skewness and kurtosis of the data were between +2 and -2 , the data have a normal distribution at the level of 0.05 .

Table 1. Descriptive statistics of pretest-posttest scores in the study groups $(n=30)$

\begin{tabular}{|c|c|c|c|c|c|c|}
\hline Variable & Condition & Group & Mean & Standard deviation & Skewness & Kurtosis \\
\hline \multirow{4}{*}{ ODD symptoms } & \multirow{2}{*}{ Pretest } & Experimental & 18.60 & 2.995 & -0.289 & -0.918 \\
\hline & & Control & 19.67 & 2.870 & -0.136 & -0.311 \\
\hline & \multirow{2}{*}{ Posttest } & Experimental & 15.73 & 2.631 & -0.073 & -1.176 \\
\hline & & Control & 19.07 & 2.251 & 0.729 & 0.264 \\
\hline \multirow{4}{*}{ Aggression } & \multirow{2}{*}{ Pretest } & Experimental & 12.37 & 1.387 & 0.422 & -0.107 \\
\hline & & Control & 11.43 & 1.555 & 0.918 & 1.044 \\
\hline & \multirow{2}{*}{ Posttest } & Experimental & 10.90 & 1.811 & 0.342 & -0.763 \\
\hline & & Control & 11.13 & 1.807 & 0.880 & 1.480 \\
\hline
\end{tabular}

The results of univariate ANCOVA to examine the differences between experimental and control groups in aggression have been reported in Table 2.

Table 2. Results of univariate ANCOVA of aggression

\begin{tabular}{ccccccc}
\hline Source & Sum of squares & Df & Mean squares & F & p & Effect size \\
\hline Pretest & 67.687 & 1 & 67.687 & 76.316 & 0.001 \\
Group & 10.053 & 1 & 10.053 & 11.334 & 0.002 \\
Error & 23.947 & 27 & 0.887 & & 0.296 & \\
\hline
\end{tabular}

According to Table 2, F-value for aggression in posttest is $11.334(\mathrm{~F}=11.334 ; \mathrm{p}<0.01$,$) which is$ significant at alpha level of 0.01 . These findings indicate that there is a significant difference between the groups in the aggression variable. The results of examining the means in the above table show that the modified mean of the experimental group in aggression (10.407) is lower than the mean of the control group in this variable by a mean of 11.626. Based on these findings, it can be said that child-parent relationship therapy was effective and reduced aggression in children. Also, the effect size in Table 2 shows that group membership explains $29.6 \%$ of the variance in aggression. Table 3 illustrates the results of univariate ANCOVA to examine the differences between the experimental and control groups in ODD symptoms.

Table 3. Results of univariate ANCOVA of ODD symptoms

\begin{tabular}{ccccccc}
\hline Source & Sum of squares & Df & Mean squares & F & P & Effect size \\
\hline Pretest & 52.748 & 1 & 52.748 & 12.372 & 0.002 \\
Group & 58.186 & 1 & 58.186 & 13.647 & 0.001 \\
Error & 115.118 & 27 & 4.264 & & 0.314 & \\
\hline
\end{tabular}


According to Table 3, F-value for ODD symptoms in post-test is $13.647(\mathrm{~F}=13.647$; $\mathrm{p}<0.01$, $)$ which is significant at alpha level of 0.01 . These findings indicate that there is a significant difference between the groups in this variable. The results of examining the means in the above table show that the modified mean of the experimental group in ODD symptoms (15.817) is lower than the mean of the control group in this variable by a mean of 18.817 . Based on these findings, it can be mentioned that child-parent relationship therapy is an effective intervention that can reduce ODD symptoms in children. Also, the effect size in Table 3 shows that group membership explains $33.6 \%$ of the variance in ODD symptoms.

\section{Conclusion}

The present study aimed to determine the effectiveness of child-parent centered play-therapy on aggression and ODD symptoms. The results of the present study showed that there was a significant difference between the aggression scores of the experimental and control groups in the post-test. Also, according to the lower mean scores of the experimental group in the post-test stage compared to the control group, it is concluded that child-parent relation therapy was effective in reducing aggression in children. This finding is supported by the results of previous studies in this field (21-23 \& 26). In explaining the above finding, it can be told that the violent atmosphere and context of the family, as well as violent parenting patterns is a cause of aggression and it can increase aggressive behavior in children; Therefore, it seems natural that by changing parenting style and improving the family context and the way members interact with each other, and especially improving parent-child interaction, we see a decrease in aggressive behaviors, so that childparent relationship therapy has a lasting effect on reducing child aggression (21). In another explanation, it can be said that in the process of training child-parent relationship therapy, parents can achieve a good understanding and acceptance of the child's behavior, and this improves parenting styles and repairs the emotional relationship between parents and child (19). By improving the family structure and enhancing the parent-child interaction, the presence of parents and the recognition and acceptance of these feelings by them, trying to understand these feelings breaks the barrier and vicious communication cycles between parent and child and as a result, many behaviors such as impulsivity and aggression are reduced in the child (23).

Another finding of the study indicates that there was a significant difference between the scores of ODD symptoms between the experimental and control groups in the post-test. Also, according to the lower mean scores of the experimental group in the post-test stage compared to the control group, it is concluded that child-parent relationship therapy was an effective treatment in reducing ODD symptoms. This finding is consistent with the results of previous studies in this field $(24,25 \& 26)$. In explaining the obtained result, it can be told that the focus of childparent relationship therapy is on improving the parent-child relationship, the child's inner self and her/his potential abilities to become optimal, and the most important goals for parents are: understanding and accepting the child's emotional world, acquiring a realistic and patient insight to self and the child, increasing parents' insight and awareness about self in relationship with the child, changing parents' perceptions of the child's behavior, learning childcentered play-therapy skills and how to create a nonjudgmental and receptive atmosphere with mutual understanding for the child and ultimately helping parents enjoy parenting (20). Therefore, it can be mentioned that training play skills, supporting and reducing the feeling of weakness and helplessness of parents and creating their sense of efficiency by creating self-esteem and self-confidence strengthens the interaction and communication between mother and child and provides the basis for reducing children's ODD symptoms (24).

Lack of follow-up tests, lack of use of qualitative tools to measure aggression and ODD symptoms in children, and not studying gender differences in the findings were the most important limitations of this study. According to the research results, it is suggested to provide child-parent relationship therapy to parents and educators who are in contact with children to promote parent-child mental health and reduce behavioral problems in children with 


\section{Quarterly Journal of Child Mental Health}

Vol. 8, No. 1, Spring 2021

other disorders. The use of the mentioned model in family and child counseling centers to provide psychological services to the community and the possibility of comparing the results to achieve the expanded clinical and local patterns along with the follow-up period is another suggestion of the present study.

\section{Ethical Considerations}

Compliance with ethical guidelines: This research has been extracted from the doctoral dissertation of Akram Akbari in the field of General Psychology at Qom branch, Islamic Azad University, that was approved on 2/24/2016 with the number 10/978. Also, its implementation license has been issued to sample people by Setareh Shahr Kindergarten and Preschool in
District 14 of Tehran with letter number 10/152 dated $12 / 9 / 2020$. Other ethical considerations such as the written consent of all participants are also emphasized in this study. Funding: This study did not receive any support from funding agencies in the public, commercial or non-profit sectors.

Authors' contribution: The first author, Ms. Akram Akbari, was responsible for writing the proposal, data collection, and implementation of trainings and initial writing of the article; Mrs. Nader Monirpour as the supervisor and Mr. Hassan Mirzahosseini as the advisor in charge of data analysis, the final writing of the article and the submission of the article.

Conflict of interest: There is no conflict of interest for the authors in this study.

Acknowledgments: The authors would like to thank all those who helped them in this research. 


\section{اثربخشى بازىدرمانى والد- محور بر يرخاشكرى و علائم اختلال نافرمانى مقابلهاى \\ اكرم اكبرى'، نادر منيريور"، حسن ميرزا حسينى

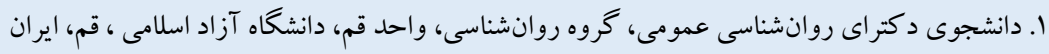

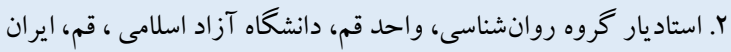

\section{جكي"}

زمينه و هدف: اختلال نافرمانى مقابلهاى در دوران كودكى و ييشدبستانى بروز بيدا مى كند و در صورت عدم درمان، هزينهاى بسيارى بر كودك،، خانو اده و جامعه تحميل مى كند؛ بنابر اين انجام مداخله هاى مناسـب براى كود كان با اين اختلال ضــرورى اســت. بدين منظور يُزوهش حاضر با هدف اثربخشى بازىدرمانى والد - محور بر يرخاشكرى و كاهش علائم اختلال نافرمانى مقابلهاى انجام شد.

روش: يزوهش حاضـر شـبه تجربى از نوع بيش آزمون بِ آزمون با گروه گواه بود. از جامعه آمارى كه شـامل تمامى كود كان ه-F سـاله با

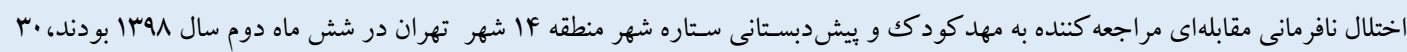

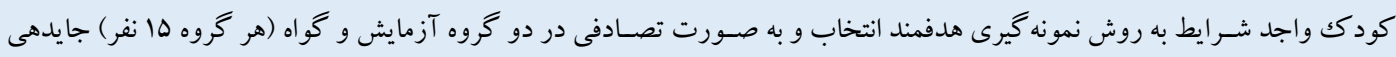

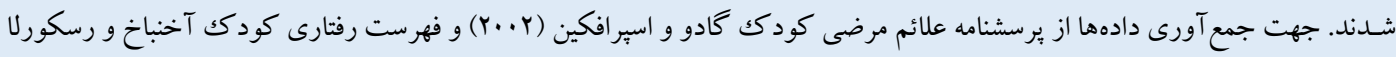

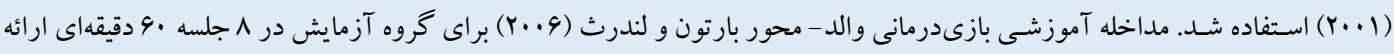

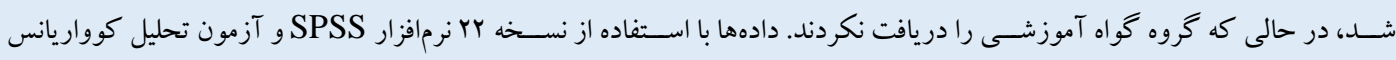
تككمتغيره در سطح معنادارى ه./ • تحليل شدند.

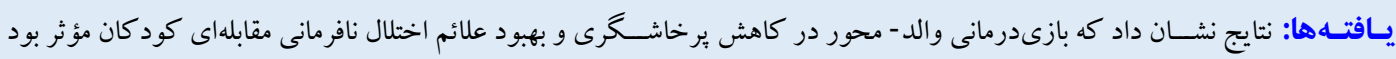
.$(\mathrm{p}<\cdot / \cdot 1)$ نتيجـهـ كيرى: بازىدرمانى والد- محور، راهبردهايى كار آمد و ســودمند براى كاهش بـرخاشــرى و بهبود اختلال نافرمانى مقابلهاى، در

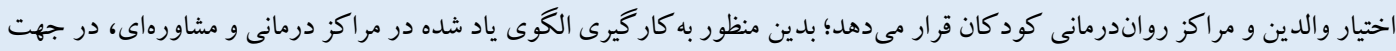
كسترش سلامت روانى، ييشنهاد مى شود.
مشخصات مقاله

كليدوازهها:

بازىدرمانى والد- محور،

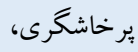

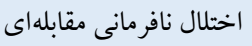

دريافت شده:

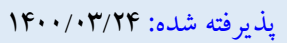

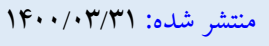

* نويسنده مسئول: نادر منيريور، استاديار كروه روانشناسى، واحد قم، دانشكاه آزاد اسلامى ، قم، ايران.

رايانامه: Monirpoor1357@gmail.com 
مقابلهاى و در نتيجه ضعف در تحصيل و برقرارى رابطه با ديخران، داراى

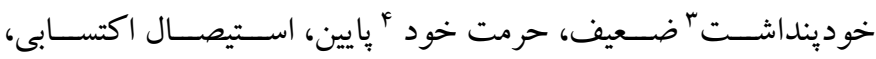

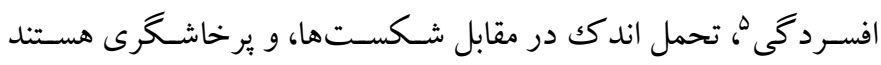

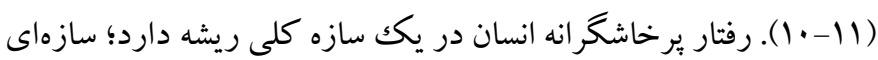

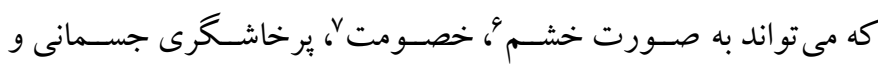

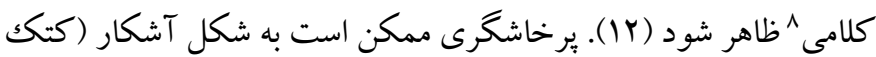

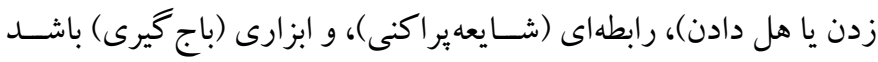

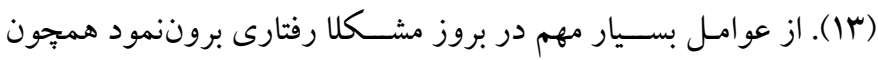

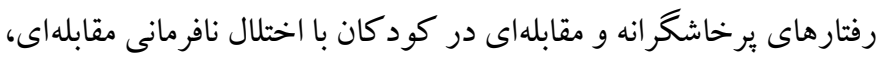

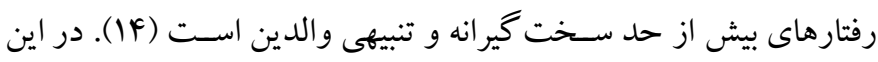

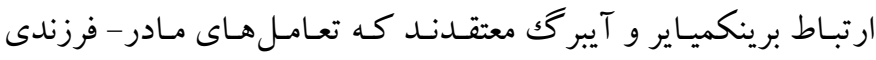

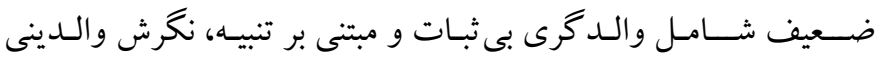

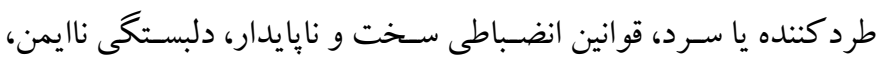

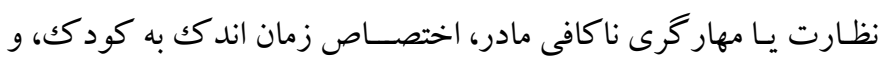
فقــان مهارت ارتبـاط مثبت با كودك به عنوان عوامل خطر و يِيشبينى كنــده اختلـال هاى رفتارى بايد مورد توجه قرار داده شــوند (ها). نتيجه

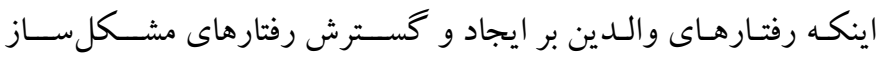

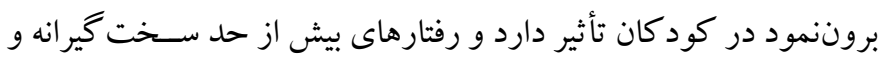

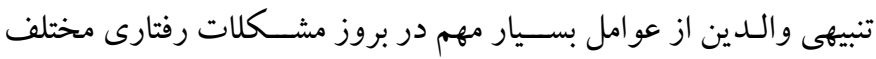

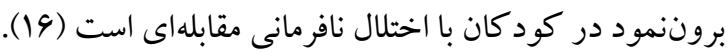

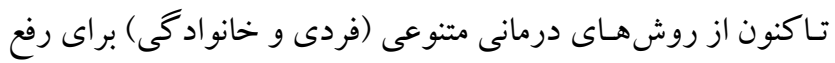

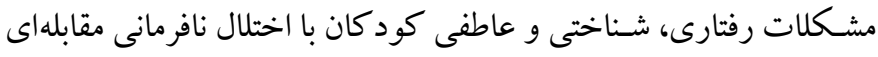

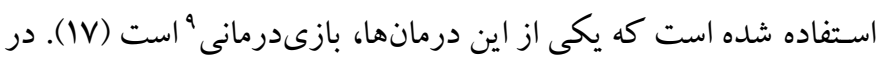

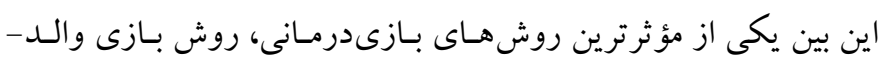

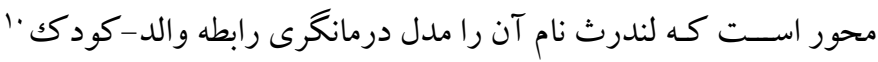

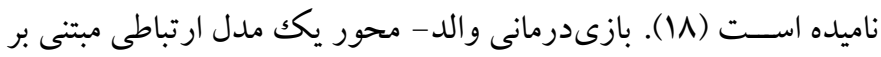

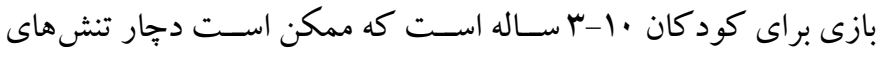

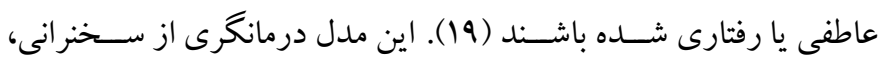
بحث، ايفاى نقش و فرايندهاى گروهى تشكيل شـده است كه والدين از

\section{Anger}

7. Hostility

8. Physical and verbal aggression

9. Play therapy

10. Child-parent relationship therapy (CPRT)
مقلمه

سـومين اختلال شـايع روانيزشـكى كود كان و نوجو انان، اختلال نافرمانى

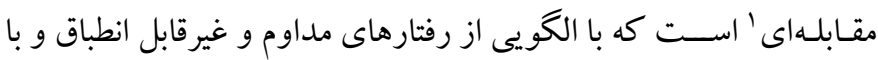

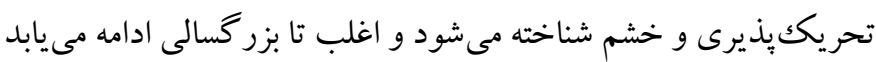

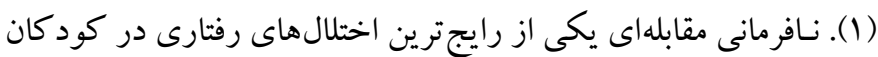

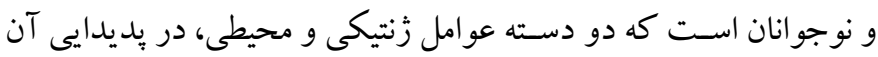

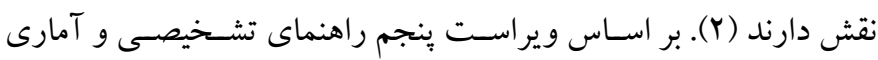

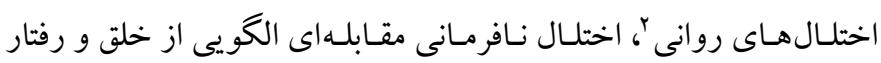

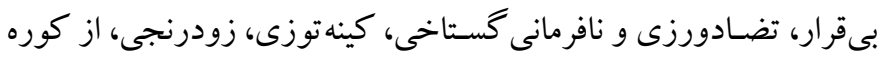

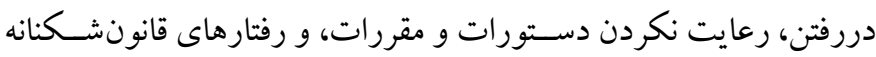
اسـت كه بيش از 9 ماه ادامه دارد و حداقل \& نشانه در تعامل با دست كم

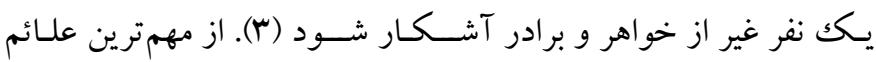

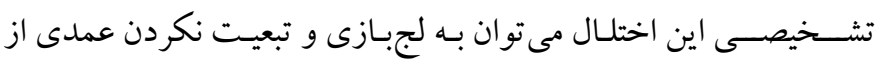

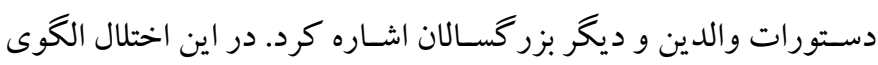

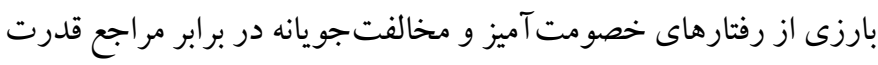

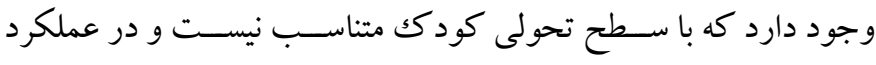

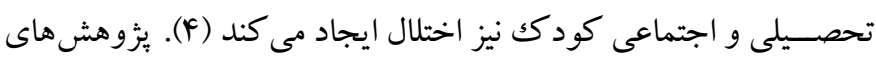

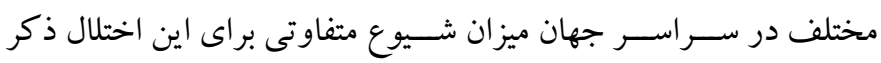

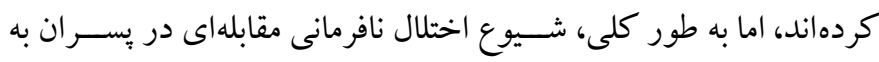
طور قابل توجهى بيشــتر از دختران بوده و ميزان شــيوع آن بين ب تا 19

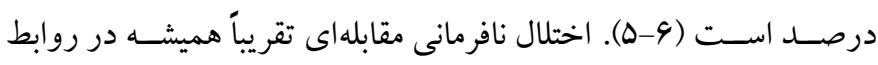

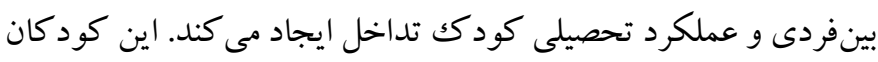

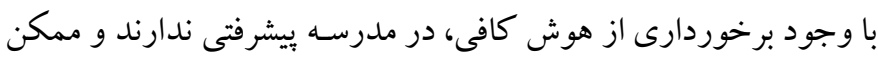

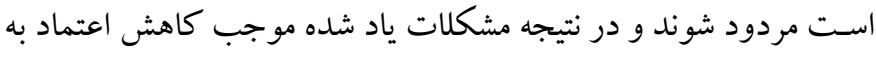

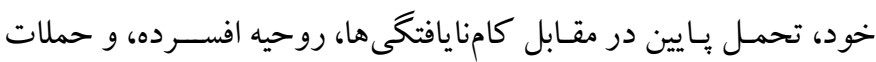
كجخلقى در آنها مى شود (V).

يُزوهش هاى سـببشـناسى، بروز اختلال نافرمانى مقابلهاى را ناشى از

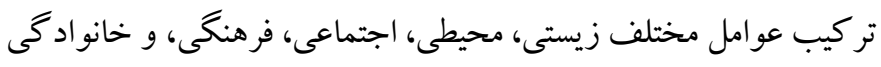

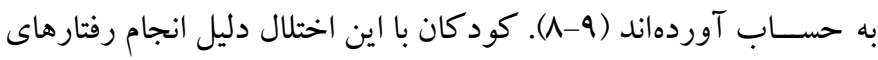

1. Oppositional defiant disorder (ODD)

2. Diagnostic and statistical manual of mental disorders-5

3. Self-concept

4. Self-esteem

5. Depression 
منطقه f| شـهر تهران در شـش ماه دوم سال ^وسا بودند؛ كه از ميان آنها

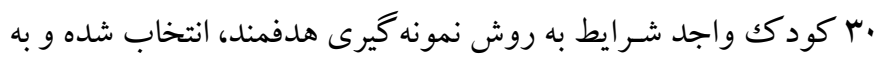

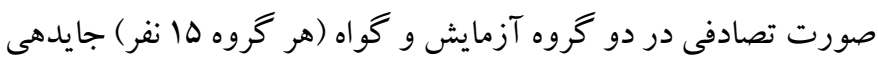

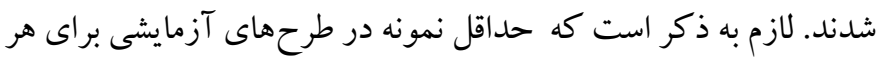

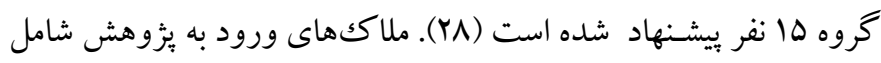
تشــخيص اختلال نافرمانى مقابلهاى كودك توســـ روانشــــاس مركز،

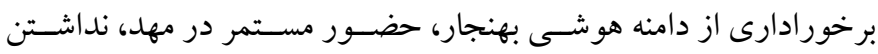

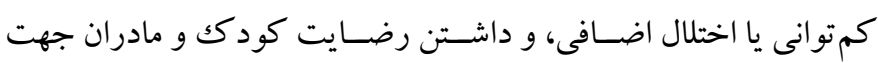

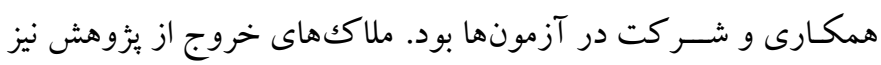
شامل غيبت يِي از دو جلسه در برنامه مداخلهاى، ابتلا به مشكلات شديد

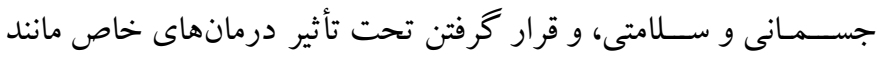
دارودرمانى براى كودكك و مادران آنان بود. ميانگين و انحر اف معيار سن

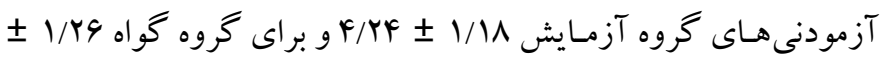

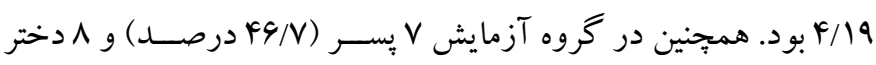

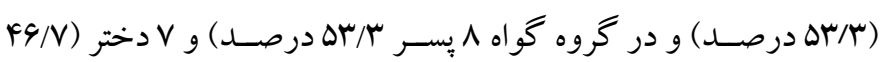
درصد) حضور داشتند.

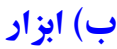
1. يرسشنامه علائم مرضى كودكى ': اين برسشنامه با هدف سنجش علائم

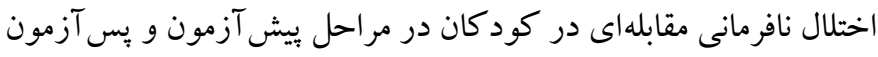
اسـتفاده شـده اسـت. فرم والدين اين برسـشنامه توسط كادو و واسبر افكين

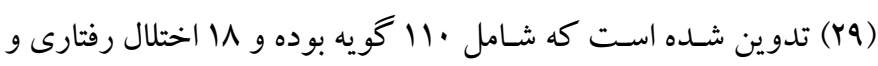

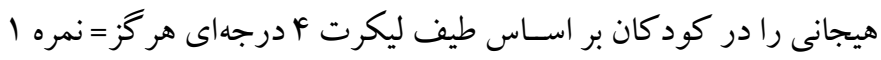

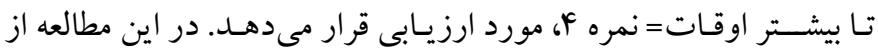

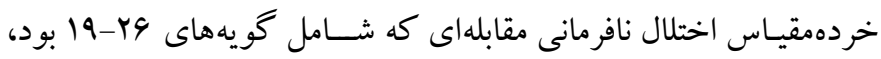

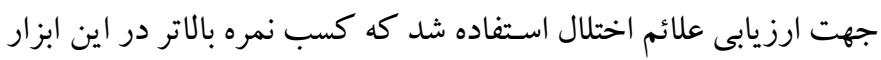

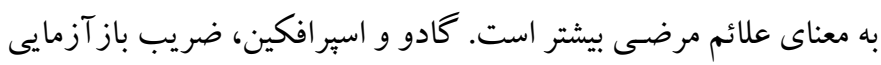

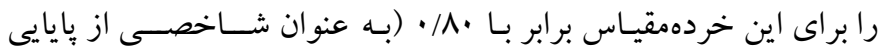

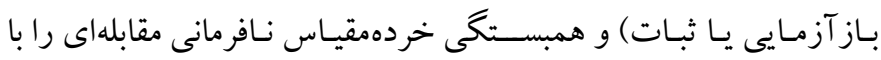
مشكلات برون بمود كود كان اN/. (به عنو ان شـاخصى از روايى همخر ا)

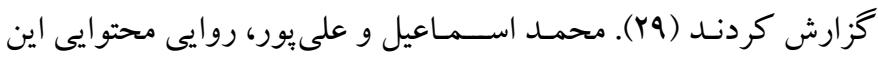
ابزار را با نظرسنجى از متخصصان مورد تأييد قرار داده و اعتبار آن رادر
طريق نقش بازى كردن، مهارتهايى را شـبيه انعكاس احسـاس، رفتار، و

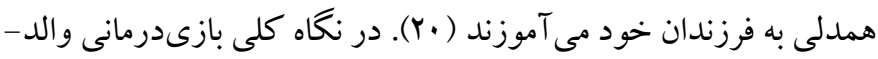

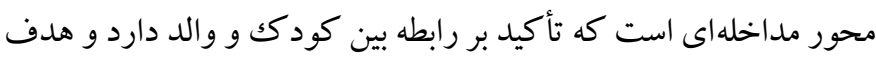

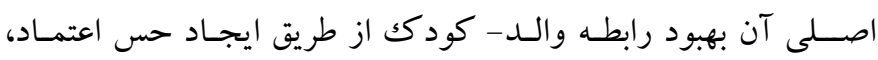

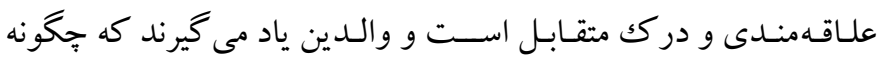

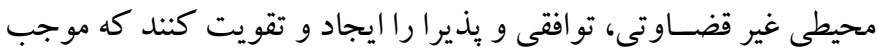

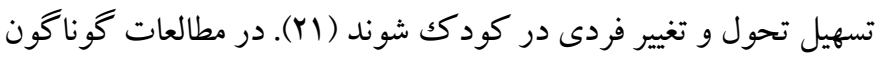

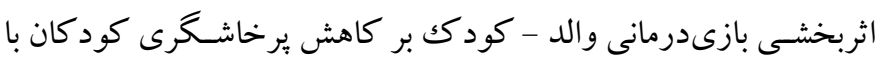

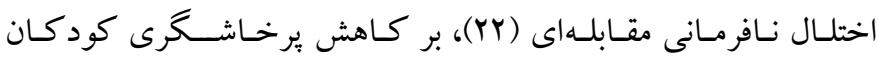

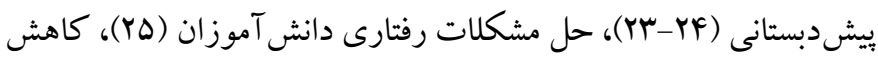

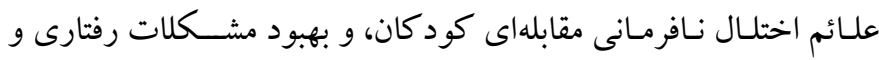

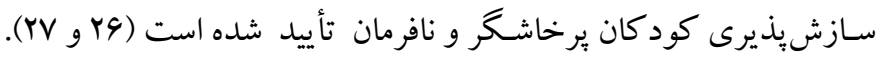

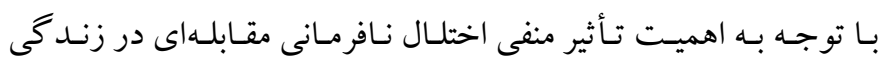

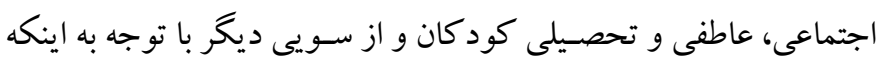
بى توجهى و عدم به كار گيرى درمانهاى مناسـب براى كاهش ائى اين اختلال

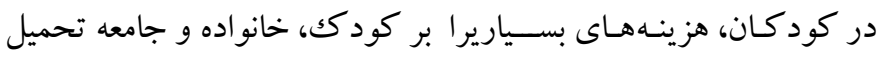

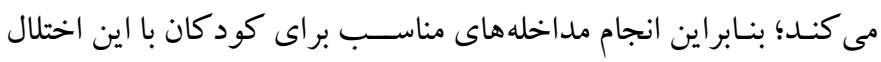

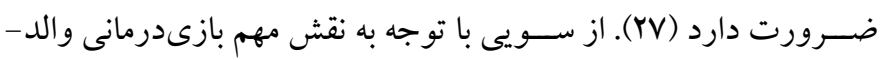

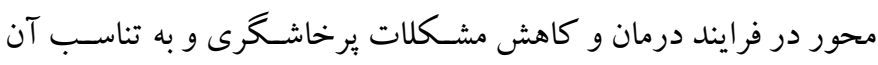

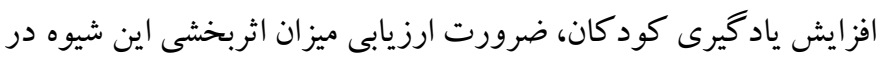

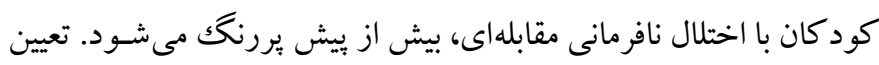

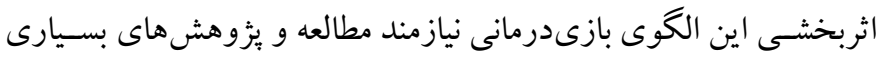

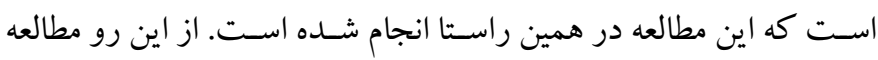

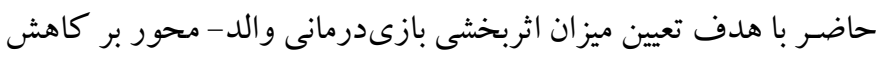
يرخاشكرى و علائم اختلال نافرمانى مقابلهاى انجام شد.

روش الف) طرح يزوهش و شـر كت كنند كان: يُزوهش حاضر شبه تجربى از

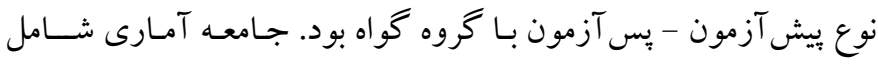

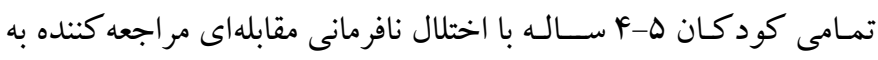
مهد كودك و ييش دبستانى ستاره شهر (زير نظر سازمان بهزيستى تهران) 
مى كنند، دجار اختلال يرخاشـكرى هستيند. آخنباخ و رسـكورلا، ضريب

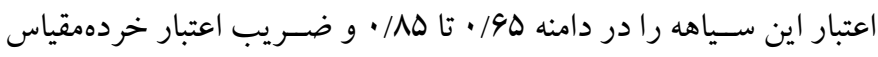

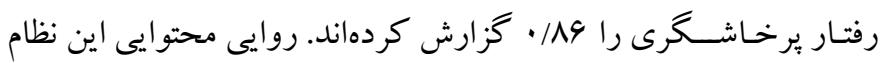

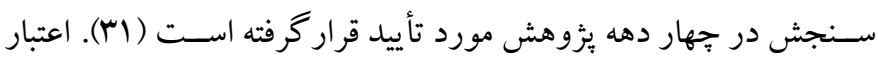

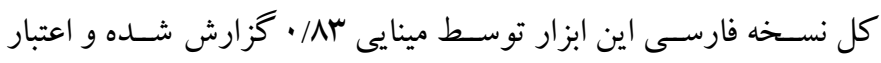

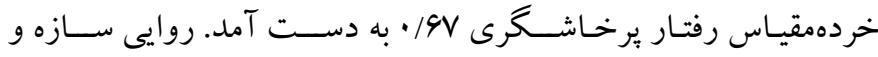
محتو ايى اين مقيـاس نيز در هنجـاريابى ايرانى توســـ مينايى مورد تأييد

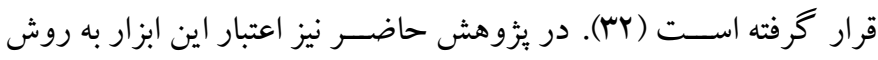

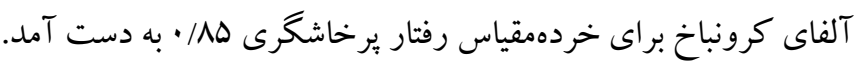

\section{ج) معرفى برنامه مداخلهاى}

جلسـات مداخله در اين مطالعه مبتنى بر جلسات بازى مدرمانى والد - محور بـارتون و لندرث (سب) بود كـه اعتبـار آن در مطـالعه عزيزى و همكاران

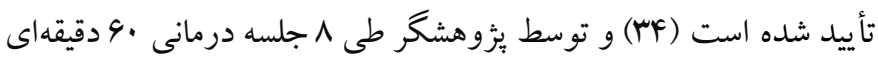

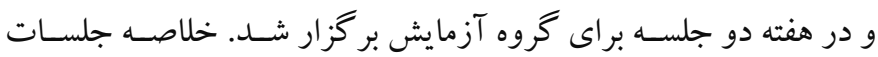
درمانى در جدول ا زَارش شده است.

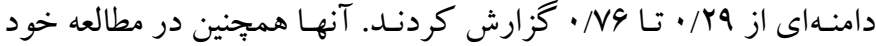
درباره ويز گى و نقطه برش خردهمقياس نافرمانى مقابلهاى برسشنامه علائم

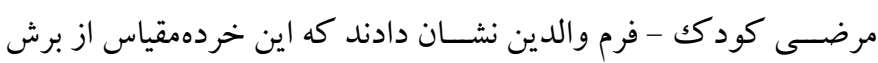

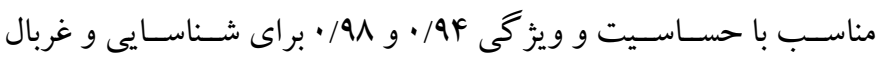

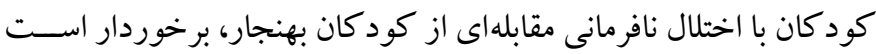

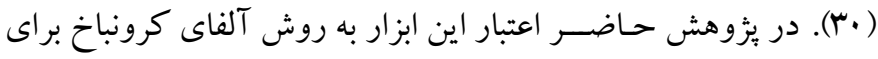

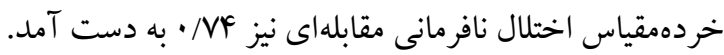

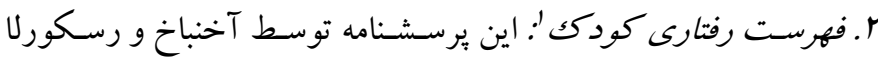

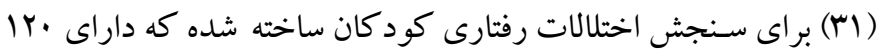

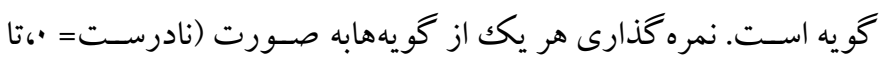

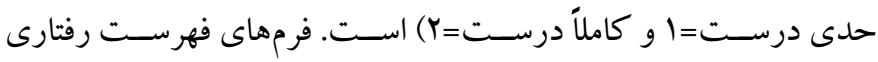

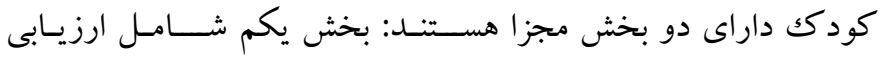

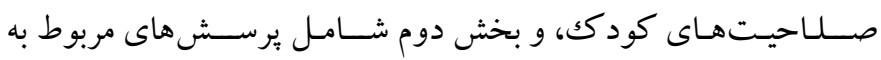

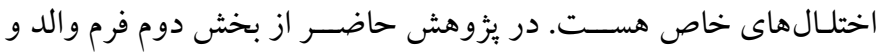

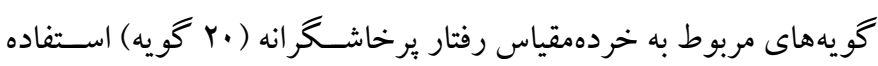

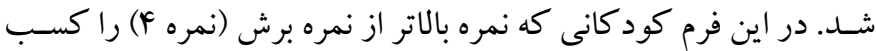

جدول 1: خلاصه جلسات درمان بازىدرمانى والد- محور (عَ)

محتوى جلسات

معارفه و آشنايى، شرح اهداف درمانى، بحث درباره لزوم ييدايش حساسيت درباره فرزندان و شكل گيرى ياسخ همدلانه، بيان موضوعات اساسى مانند تشويق و تقويت والدين، همدلى با والدين،

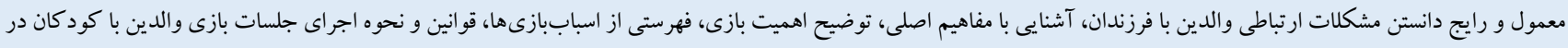
منزل، مكان و زمان بازى.

تشخيص جهار احساس اصلى (شادى، غم، خشم، و ترس)، ايفاى نقش ياسخ همدلانه، آموزش اصول بازىدرمانخرى والدينى، آموزش پاسخدهى همدلانه به كودك، تمرين ياسخدهى همدلانه، و وتكميل بر گهष هاسخ احساسى.

آموزش اصول بازى مانند اينكه كودكك در جلسات بازى هدايتخر است؛ توجه به احساسات كودكك از طريق حالتهاى جهره، بدن، لحن صدا و كلام كودك؛؛ انعكاس ادراكك والدين از باز

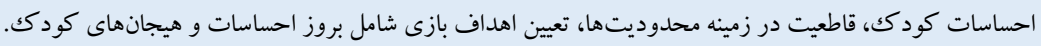

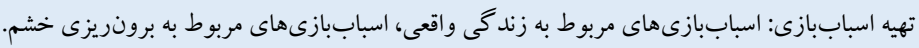

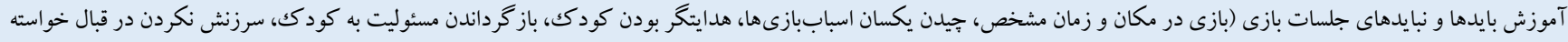

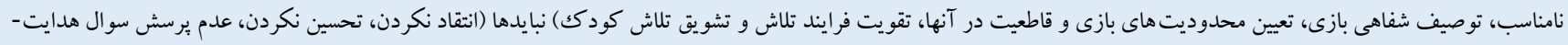

$$
\begin{aligned}
& \text { كر انه، عدم قطع جلسات بازى، عدم آموزش و اطلاعات). }
\end{aligned}
$$

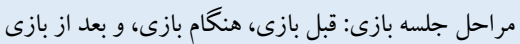

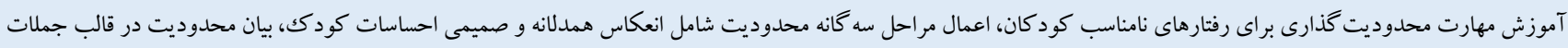

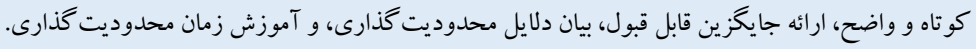


روش هاى حق انتخاب دادن (حق انتخاب دادن به صورت ساده و قدرت بخشيدن به كودك،، حق انتخاب دادن به عنوان بيامد مثبت و حق انتخاب دادن براى تقويت قوانين خانه)، و فهرست مهارتهاى جلسه بازى.

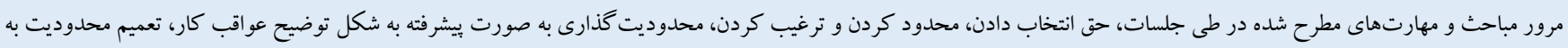
خارج از جلسه، و اجراى يس بـ آزمون.

آزمون تحليل كوواريانس تككمتغيره در ســحح معنادارى ه• • اسـتفاده

\section{يافتهها}

مـيـانگين و انحراف معيـار نمرات بيش آزمون- بِ آزمون متغيرهـاى

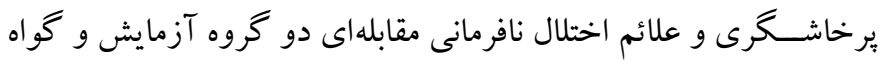

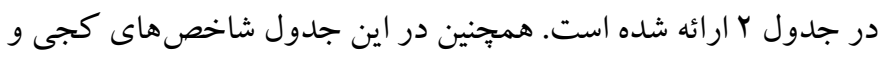

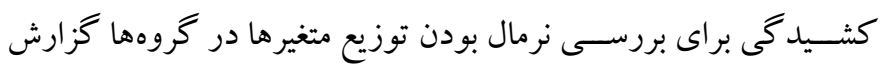

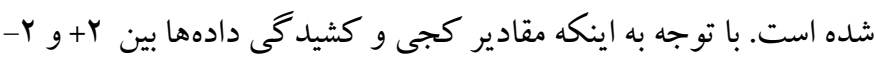
است، دادهها در سطح ه •/• از توزيع نرمال برخوردارند.
د) روش اجرا: يس از انتخـاب نمونـه و جـايـدهى آنها بـه گروههـاى

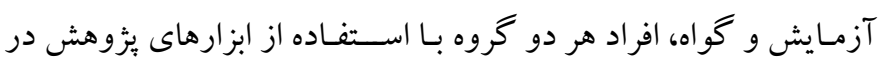

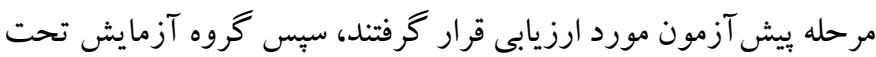
مداخله هشت جلسه بازىدرمانى والدمحور (هر جلسه •9 دقيقه و هفتهاى

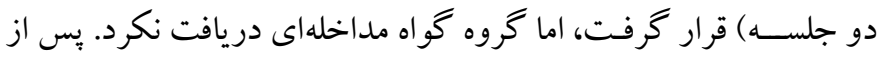

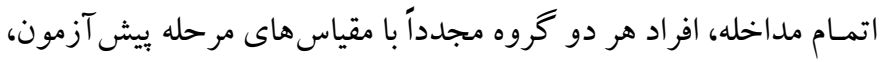

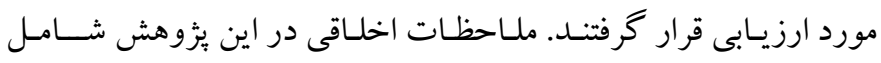

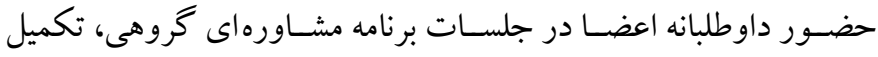
كردن يرسشـنامهها با ميل و رغبت توسط اعضا، برنامهريزى مناسب براى إس

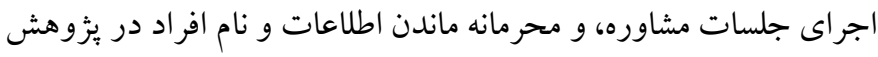
رعايت شــده اسـت. جهت تحليل دادهها از نسـخه با نرمافزار SPSS و

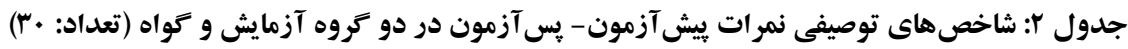

\begin{tabular}{|c|c|c|c|c|c|c|}
\hline كشيدكى & كجى & انحراف معيار & ميانكين & كروه & وضعيت & متغير \\
\hline.$- / 911$ & $-\cdot / Y \wedge q$ & $r / 99 \Delta$ & $1 N / 9$. & آزمايش & \multirow[b]{2}{*}{ يِيش آزمون } & \multirow{4}{*}{ نافرمانى مقابلهاى } \\
\hline$-\cdot / \mu 11$ & -./Irq & r/AV. & $19 / 9 V$ & كواه & & \\
\hline$-1 / 1 V 9$ & $-\cdot / \cdot v r$ & $r / 941$ & $10 / V r$ & آزمايش & \multirow[b]{2}{*}{ پِ آزمون } & \\
\hline.$- /$ Ta & - /VYq & $r / Y \Delta 1$ & $19 / \cdot V$ & كواه & & \\
\hline$-\cdot / 1 \cdot v$ & . IFYY & I/TAV & $I r / r V$ & آزمايش & \multirow[b]{2}{*}{ يِيش آزمون } & \multirow{4}{*}{ يرخاشكرى } \\
\hline $1 / \cdot F F$ & $\cdot / \Lambda$ & $1 / \Delta \Delta \Delta$ & $11 / 4 \pi$ & كواه & & \\
\hline- - NGT & D MFY & $1 / 111$ & $1 . / 9$. & آزمايش & \multirow{2}{*}{ پֶس آزمون } & \\
\hline $1 / F \lambda$. & . /M. & $1 / A \cdot V$ & $11 / 1 \pi$ & كواه & & \\
\hline
\end{tabular}

همخًى واريـانس متغير وابســته برخاشــرى در كروهها نشــان داد كه

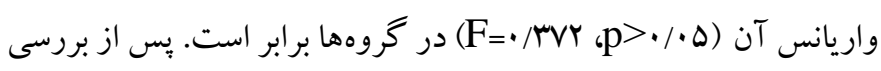

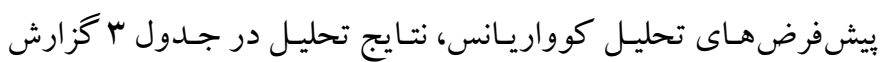
شده است.
جهت بررسـى اثربخشـى بازى برومانى والد- محور بر برخاشــرى كود كان نيز از آزمون تحليل كوواريانس تككمتغيره اسـتفاده شــد. نتايج آزمون بررسى همخنى شيب رگرسيون ييش آزمون و يس آزمون نمرات در گروه آزمايش و گواه نشـان داد كه شـيب رگرسـيون در هر دو گروه

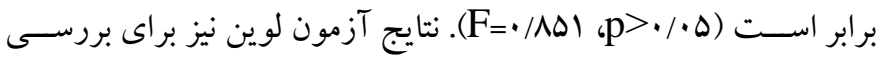


جدول ז: نتايج تحليل كواريانس تكمتغيرى براى بررسى تفاوت كروه آزمايش و كواه در يرخاشكرى

\begin{tabular}{|c|c|c|c|c|c|c|}
\hline اندازه اثر & $\mathbf{P}$ & مقدار F F & ميانكين مجذورات & درجه آزادى & مجموع مجذورات & منبع تغييرات \\
\hline$\cdot / N r q$ &.$/ \cdot 1$ & $V 9 / \pi 19$ & $9 \mathrm{~V} / 9 \mathrm{NV}$ & 1 & GV/GAV & بيش آزمون \\
\hline \multirow[t]{2}{*}{$\cdot / 499$} & $\% r$ & $11 / / \mu_{F}$ & $1 . / \cdot \Delta r$ & 1 & $1 . / . \Delta r$ & عضويت گروهى \\
\hline & & & $\cdot / M V$ & TV & $\mathrm{rm} / \mathrm{QqV}$ & خططا \\
\hline
\end{tabular}

به منظور بررسسى اثربخشى بازىدرمانى والد- محور بر علائم اختلال نـافرمـانى مقـابلـهاى كودكـان، از آزمون تحليـل كوواريـانس تككمتغيره اسـتفاده شـد. نتايج آزمون بررسى همخنى شيب ركرسيون بيش آزمون و يس آزمون نمرات در گروه آزمايش و گ اه نشان داد كه شيب ركرسيون

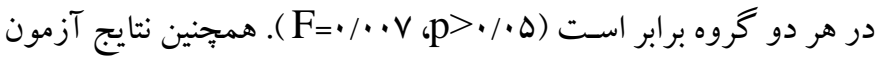
لوين براى بررسـى همخنى واريانس متغير وابســـه علائم اختلال نافرمانى

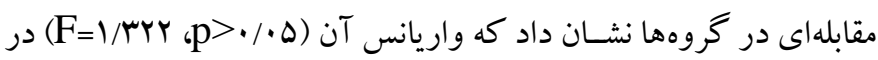
گروهها برابر است. يس از بررسى بيش فرض هاى تحليل كوواريانس، در جدول أنتايج تحليل گزارش شده است.
بـا توجه به نتايج جدول ب آماره F براى يرخاشــرى در يس آزمون

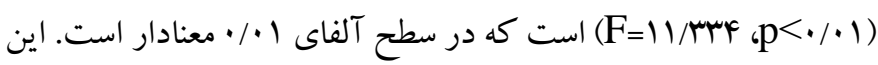

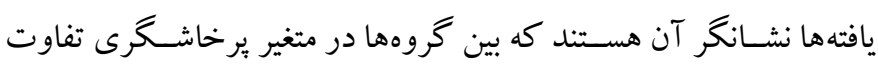
معنـادارى وجود دارد. نتـايج بررســى ميـانكينها در جدول فوق نشــان

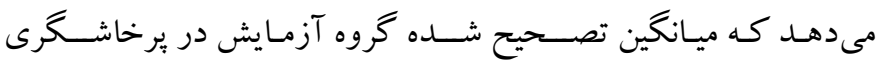

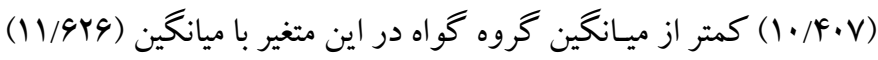
اســت. با توجه به اين يافتها مى توان كفت كه بازىدرمانى والد- محور

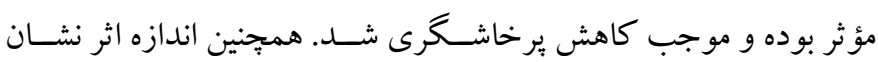

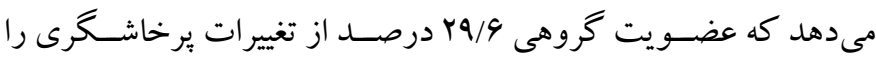
تبيين مى كند.

جدول ع: نتايج تحليل كوواريانس تكمتغيرى براى بررسى تفاوت كروه آزمايش و كواه در نافرمانى مقابلهاى

\begin{tabular}{|c|c|c|c|c|c|c|}
\hline اندازه اثر & $\mathbf{P}$ & Fقدار F F F & ميانكين مجذورات & درجه آزادى & مجموع مجذورات & منبع تغييرات \\
\hline / MIF & $\% r$ & $I r / r V r$ & $\Delta r / V A F$ & 1 & $\Delta r / V F A$ & ييش آزمون \\
\hline \multirow[t]{2}{*}{ ( } &.$/ .1$ & $1 \mathrm{~W} / 9 \mathrm{FV}$ & $\Delta \Lambda / \backslash \Lambda Q$ & 1 & $\Delta \Lambda / \backslash \Lambda \varphi$ & عضويت گروهى \\
\hline & & & F/TGF & rV & $\| \Delta / 111$ & خطا \\
\hline
\end{tabular}

\section{بحث و نتيجه كيرى}

هـدف مطالعـه حـاضــر تعيين اثربخشــى بـازىدرمـانى والـد - محور بر يرخاشـرى و اختلال نافرمانى مقابلهاى بود. اولين يافته يزٔوهش نشان داد

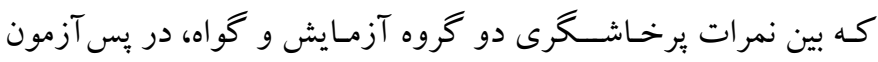
تفـاوت معنـادارى وجود دارد. همجينين بـا توجـه به پيايين تر بودن ميانگين نمرات كروه آزمـايش در مرحلـه يس آزمون در مقـايســهـ بـا افراد كروه

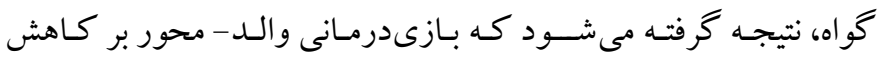
يرخاشـرى كود كان نيز مؤثر بود. نتيجه به دسـت آمده با نتايج مطالعات بيشـين در اين زمينه همسو است. براى مثال مطالعات انجام شده ( (YD-Y) نشان دادهاند كه بازىدرمانى والد - كودك بر يرخاشخرى دانش آموزان
بـا توجـه به نتايج جدول F F آماره F براى اختلال نافرمانى مقابلهاى در

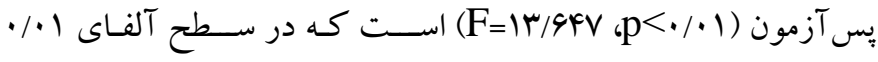
معنادار اسـت. اين يافته ها نشـانكر آن هستند كه بين گروهها در اين متغير تفـاوت معنـادارى وجود دارد. نتـايج بررسـى ميـانگينها در جدول فوق نشان مىدهد كه ميانگين تصحيح شده گروه آزمايش در اختلال نافرمانى

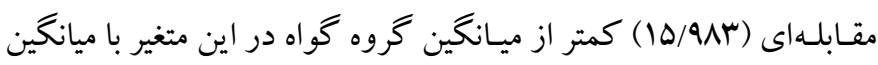
اســت بـا توجـه به اين يافته ها مى توان كفت كه بازىدرمانى (IN/NIV) والـدـ- محور مؤثر بوده و موجـب كـاهش اختلـال نـافرمـانى مقــابلـهاى كود كان شد. همجينين اندازه اثر به دست آمده نشان مى دهد كه عضويت كروهى /4/ مس درصد از تغييرات اختلال نافرمانى مقابلهاى را تبيين مى كند. 
بـازىدرمـانى متمركز بر والـدين، روشــى اثربخشتر از بـازىدرمـانى

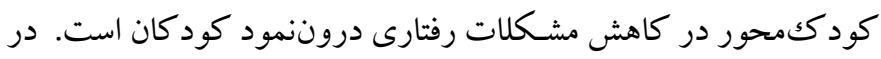

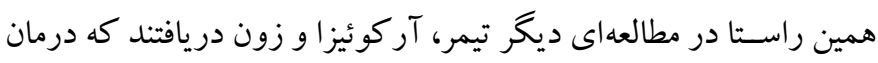

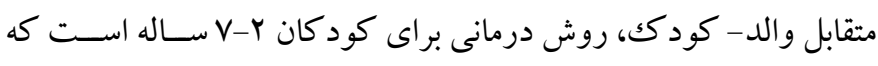
هدف آن تغيير محيط اجتماعى كودك اســت تا باعث تقويت رفتارهاى

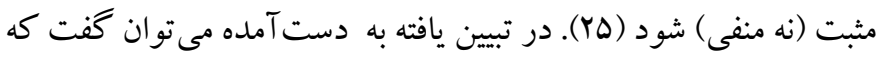

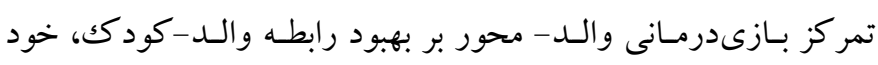

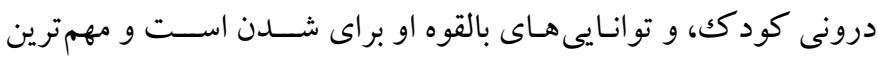

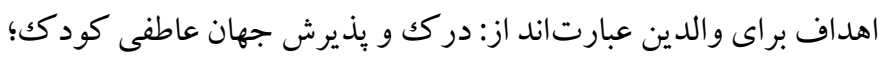

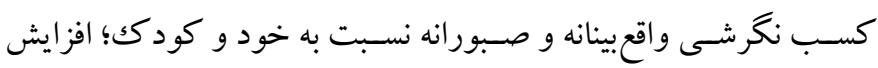
بينش و آكاهى والدين نسبت به خود در ارتباط با كودكك؛ تغيير ادراكات

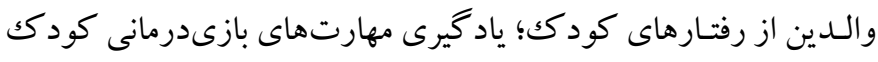

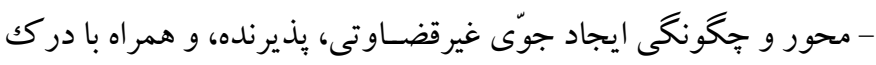

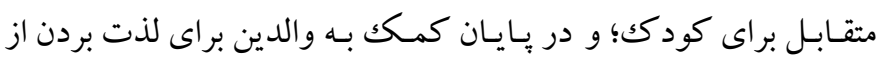

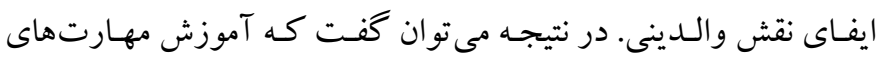

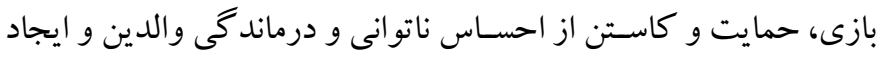

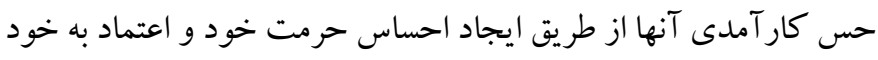

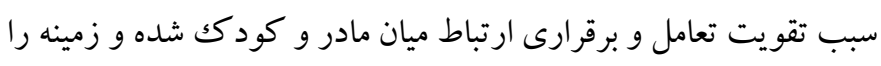

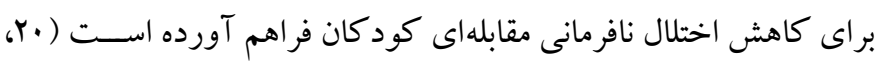
(rF از مهـم ترين محسدوديستهـاى اين بثزوهش، عــدم بركزارى دوره

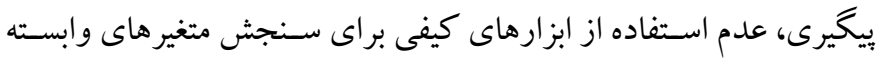

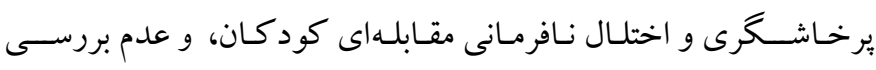

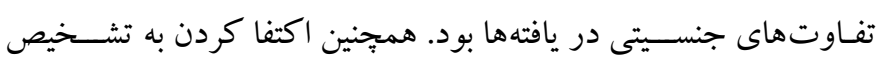

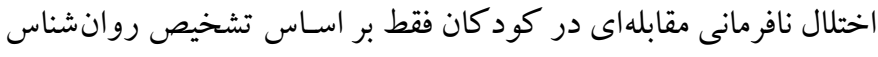

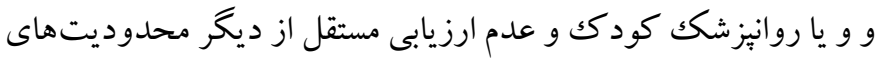

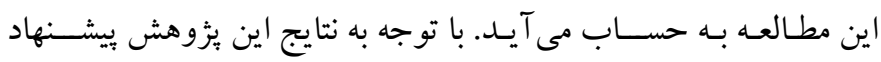

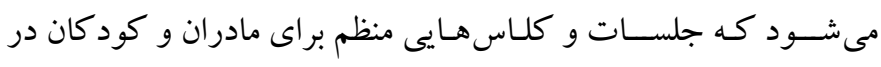

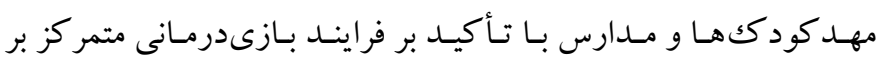

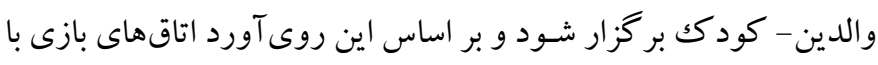
وسـايل و ابزارهاى اســاندارد در مدارس داير شــوند. در ضــمن ارائه

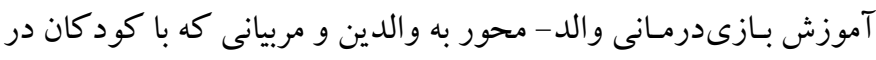

مــدارس مقطع ابتـدايى تأثير داشــ؛ برنـامه بازىدرمانى مبتنى بر رابطه

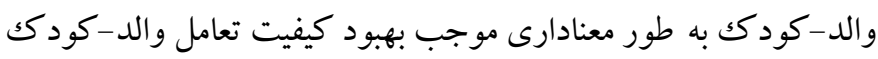

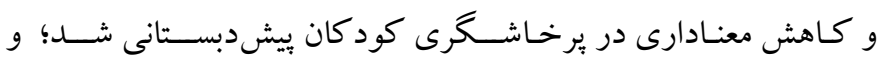

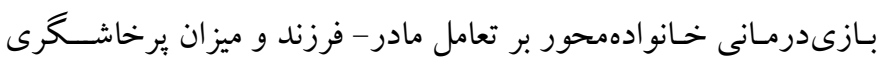

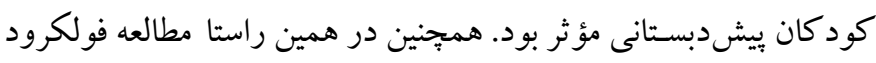

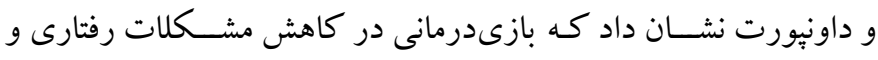

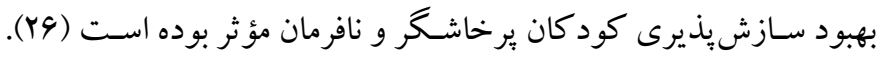

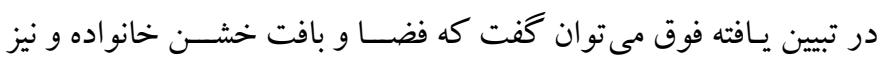

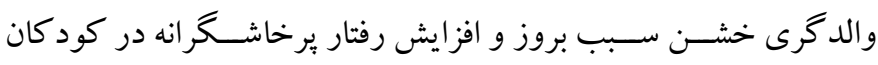

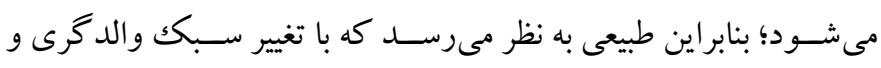

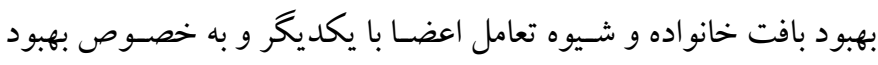

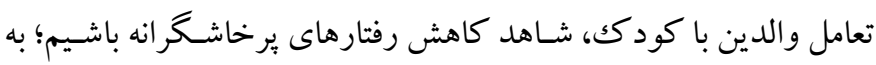

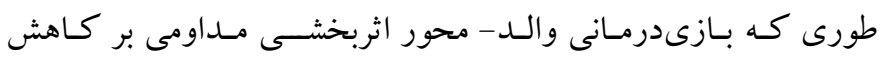

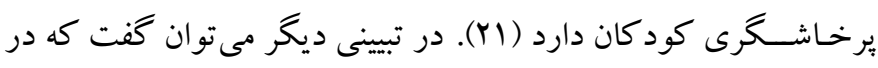

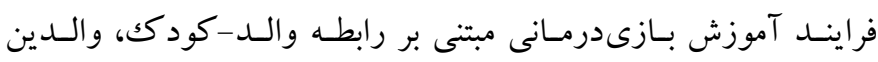

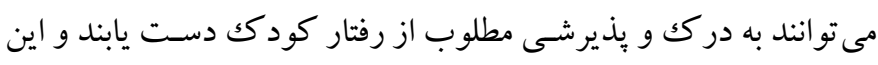
موضـوع سـبب بهبود سـبكك هاى والدگرى و ترميم روابط عاطفى ميان

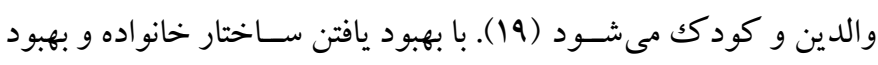

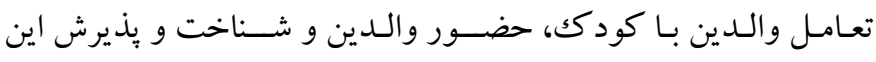

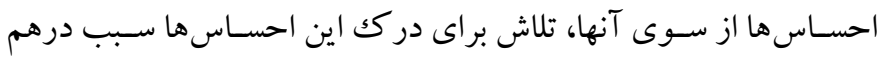
شكستن بازدارى و جرخه هاى ارتباطى معيوب بين والد و كود كك شده و

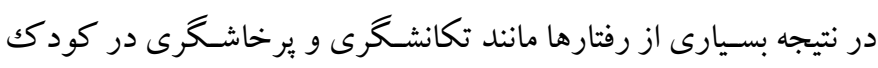

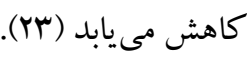

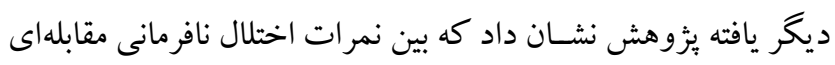

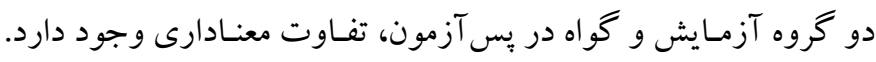

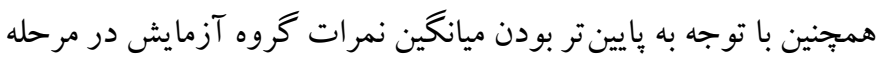

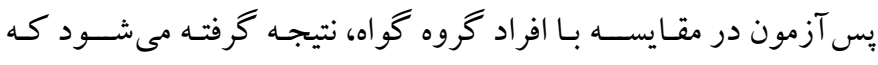
بـازىدرمـانى والـد- محور بر كـاهش اختلال نافرمانى مقابلهاى مؤثر بود. يافته فوق با نتايج مطالعات بيشـين در اين زمينه همسـو است. به طور مثال

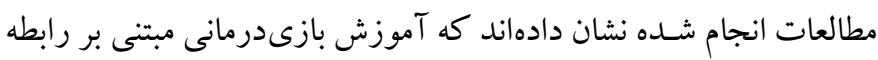
و الد-كود كك به مادران به طور معنادارى موجب كاهش مشكلات رفتارى

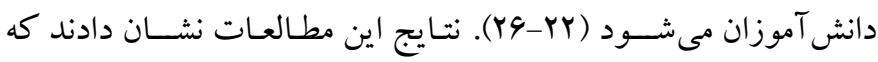


ملاحظات اخلاقى

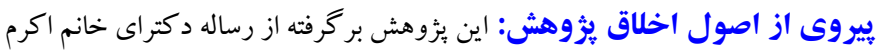

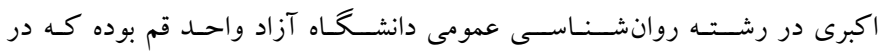

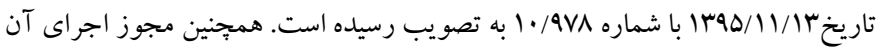
بر روى افراد نمونه از سوى مهد كودك و وييشدبستانى ستاره شهر منطقه fا شهر تهران

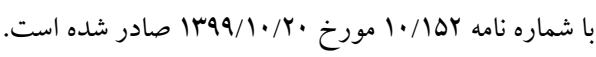

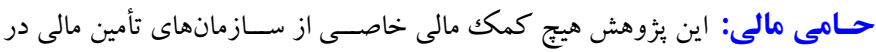
بخشهاى دولتى، تجارى يا غير انتفاعى دريافت نكرده است.

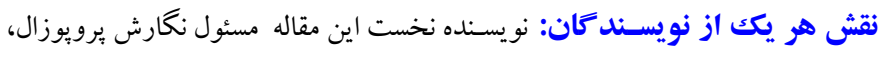

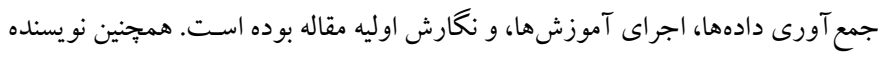
دوم در نقش استاد راهنما و نويسنده سوم در نقش استاد مشاور در اين مقاله نقش ايفا

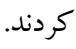
تضاد منافع: هيج گونه تضاد منافع براى نويسند كان در اين مطالعه وجود ندارد.

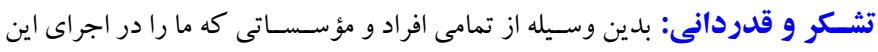
يُزوهش يارى دادند، كمال تشكر و قدردانى به عمل مى آيد.
ارتباط هستند در جهت گسترش سلامت روانى والد- كودك و كاهش

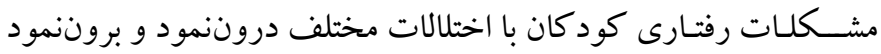

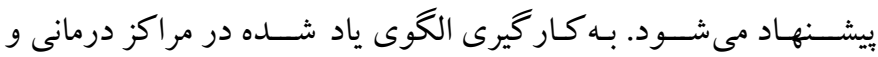

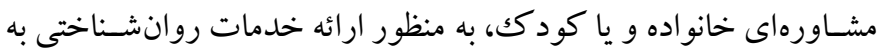

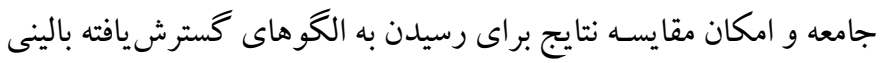
و بومى همر اه با دوره بيخيرى از ديخر بيشـنهادهاى مطالعه حاضـر اسـت.

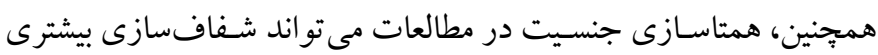

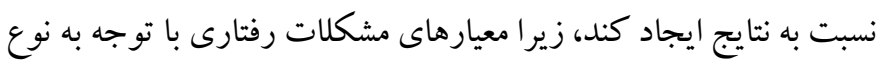
جنسيت مى تواند متفاوت باشد. 


\section{References}

1. Sharifi Esfahani M, Farahbakhsh K, Esmaeili M, Salimi Bajestani H, Asgari M. Exploring of moderating factors of oppositional defiant disorder: A Qualitative Research. Journal of Research in Behavioural Sciences. 2020; 18(3):336-348. [Persian]. [Link]

2. Shiroodaghaei E, Amir Fakhraei A, Zarei E. Comparison of the effectiveness of cognitivebehavioral play therapy and parent-child Interaction therapy on executive functions and parent-child interaction in children with oppositional defiant disorder. J Child Ment Health. 2020; 7(2):79-95. [Persian]. [Link]

3. American Psychiatric Association. Diagnostic and statistical manual of mental disorders 5th ed. Arlington, VA: American Psychiatric Association. 2013. [Link]

4. Kimonis ER, Frick PJ. Oppositional defiant disorder and conduct disorder grown-up. JDBP. 2010; 31(3):244-254. [Link]

5. Demmer DH, Hooley M, Sheen J, McGillivray JA, Lum JA. Sex differences in the prevalence of oppositional defiant disorder during middle childhood: a meta-analysis. Journal of abnormal child psychology. 2017; 45(2):313-325. [Link]

6. López-Villalobos JA, Andrés-De Llano JM, Rodríguez-Molinero L, Garrido-Redondo M, Sacristán-Martín AM, Martínez-Rivera MT, et al. Prevalence of oppositional defiant disorder in Spain. Revista de Psiquiatría y Salud Mental (English Edition). 2014; 7(2):80-87. [Link]

7. Vahia VN. Diagnostic and statistical manual of mental disorders 5: A quick glance. Indian J Psychiatry. 2013; 55(3):220-223. [Link]

8. McKinney C, Renk K. Emerging research and theory in the etiology of oppositional defiant disorder: Current concerns and future directions. IJBCT. 2007; 3(3):349-371. [Link]

9. Christensen LL, Baker BL. The Etiology of Oppositional Defiant Disorder for Children with and without Intellectual Disabilities: A Preliminary Analysis. J Ment Health Res Intellect Disabil. 2021:120. [Link]

10. Jahanbakhsh M. Effect of attachment-based therapy on mental health in girls with attachment problems. Journal of Fundamentals of Mental Health. 2012; 14(54):51-140. [Persian]. [Link]

11. Sharifi-Daramady $P$, Bagean-Kulemarez MJ, Padervand H, Gravand F. The effect of impulse control training on impulsiveness and reduce the symptoms of students with oppositional deficit disorder. Journal of Clinical Psychology. 2014; 5(4):29-42. [Persian]. [Link]

12. Khaneh Keshi A, Khanmohammadi Otaghsara A, Malekian S. The relationship of emotional instability, pro-social behavior and aggression with addiction readiness of secondary high school boy students. Quarterly Social Psychology Research. 2018; 7(28):123-145. [Persian]. [1Link]

13. Saeedi E, Sabourimoghadam H, Hashemi T. Predicting the relationship between emotional intelligence and anger rumination with the aggression of Tabriz university students. Quarterly Social Psychology Research. 2020; 10(38):65-82. [Persian].[Link]

14. Kawabata Y, Tseng W-L, Gau SS-F. Symptoms of attention-deficit/hyperactivity disorder and social and school adjustment: The moderating roles of age and parenting. J Abnorm Child Psychol. 2012; 40(2):177188.[Link]

15. Brinkmeyer MY, Eyberg SM. Parent-child interaction therapy for oppositional children. 2003. [Llink]

16. Amiri M, Movallali G, Nesaiyan A, Hejazi M, Assady Gandomani R. Effect of behavior management training for mothers with children having ODD Symptoms. Archives of Rehabilitation. 2017; 18(2):84-97. [Persian]. [Link]

17. HosseinKhanzadeh AA. The Effect of child-centered play therapy on the self-efficacy in peer relations among students with oppositional defiant disorder symptoms. J Child Ment Health. 2017; 4(3):49-59. [Persian]. [link]

18. Azizi A, Fatehizade M, Ahmadi A, Jazayeri R. Effect of child-parent relationship therapy on parenting stress and empowerment of parents with children with Attention Deficit/Hyperactivity Disorder. Fam Couns Psychother. 2018; 8(1):27-46. [Persian]. [link]

19. Edwards NA, Sullivan JM, Meany-Walen K, Kantor KR. Child parent relationship training: Parents' perceptions of process and outcome. International Journal of Play Therapy. 2010; 19(3):159-173. [Link]

20. Adili S, Mirzaie Ranjbar R, Abedi A. The effectiveness of filial therapy on the quality of parentchild Interactions and health-related quality of life in children with behavioral/emotional problems. Journal of Exceptional Children. 2019; 19(1):59-70. [Persian]. [Link] 
21. Kinsworthy S, Garza Y. Filial therapy with victims of family violence: A phenomenological study. JOFV. 2010; 25(4):423-429. [Link]

22. Yosefishahir N, Azmodeh M, Vahedi S, Livarjani S. The effectiveness of parent-child play therapy on aggression, anxiety and social fear in children with oppositional defiant disorder. Cultural Psychology. 2020; 4(1):139-156. [Persian]. [Link]

23. Kiafar MS, Aminyazdi SA, Karshki H. The effectiveness of family-based play therapy on the improvement of mother-child interaction and decreasing aggression in preschool Mashhad city. Research in Clinical Psychology and Counseling. 2014; 4(2):4-18. [Persian]. [Link]

24. Dabir M, Asadzadeh PD, H. Hatami PD, H. R. The Effectiveness of Administering Child Parent Relationship Therapy (based on Landreth Model) to Mothers in Reducing the Behavioral Problems of their School Children. Quarterly Journal of Family and Research. 2020; 17(1):83-102. [Persian]. [Link]

25. Timmer SG, Urquiza AJ, Zone SR. Play therapy for oppositional/defiant children: Parent-child interaction therapy. 2015. [Link]

26. Foulkrod K, Davenport BR. An examination of empirically informed practice within case reports of play therapy with aggressive and oppositional children. International Journal of play therapy. 2010; 19(3):144-158. [Link]

27. Stringaris A, Zavos H, Leibenluft E, Maughan B, Eley TC. Adolescent irritability: Phenotypic associations and genetic links with depressed mood.
The American Journal of Psychiatry, 170(7), 810-820. [Link]

28. Delavar A. Research methodology in psychology and education. Tehran: Virayesh; 2015. [Persian]. [Link]

29. Gadow KD, Sprafkin JN. Child symptom inventory 4: Screening and norms manual: Checkmate Plus; 2002. [Link]

30. Mohamadesmaiel E, Alipour A. A preliminary study on the reliability, validity and cut off points of the disorders of children symptom inventory-4 (CSI-4). Journal of Exceptional Children. 2002; 2(3):239-254. [Persian]. [Link]

31. Achenbach TM, Rescorla L. Manual for the ASEBA school-age forms \& profiles: An integrated system of multi-informant assessment: Aseba Burlington, VT: 2001. [Link]

32. Minaee A. Adaptation and standardization of child behavior checklist, Youth Self-report, and Teacher's Report Forms. Journal of Exceptional Children. 2006; 6(1):529-558. [Persian]. [Link]

33. Bratton SC, Landreth GL. Child parent relationship therapy (CPRT) treatment manual: A 10-session filial therapy model for training parents: Routledge; 2006. [Link]

34. Azizi A, Karimipoor BA, Rahmani S, Veisi F. Comparing the eEfficacy of child-parent relationship therapy (CPRT) and family-focused therapy (FFT) on function of families with children with oppositional defiant disorder (ODD). J Child Ment Health. 2016; 3(2):9-20. [Persian]. [Link] 